\title{
Cascaded-like High-Step-Down Converter with Single Switch and Leakage Energy Recycling in Single-Stage Structure
}

\author{
Chih-Lung Shen*(D), Li-Zhong Chen, Tsung-Yung Chuang and Yu-Shan Liang
}

check for

updates

Citation: Shen, C.-L.; Chen, L.-Z.;

Chuang, T.-Y.; Liang, Y.-S.

Cascaded-like High-Step-Down

Converter with Single Switch and

Leakage Energy Recycling in

Single-Stage Structure. Electronics

2022, 11, 352. https://doi.org/

$10.3390 /$ electronics 11030352

Academic Editor:

Mohamed Benbouzid

Received: 29 December 2021

Accepted: 21 January 2022

Published: 24 January 2022

Publisher's Note: MDPI stays neutral with regard to jurisdictional claims in published maps and institutional affiliations.

Copyright: (C) 2022 by the authors. Licensee MDPI, Basel, Switzerland. This article is an open access article distributed under the terms and conditions of the Creative Commons Attribution (CC BY) license (https:/ / creativecommons.org/licenses/by/ $4.0 /)$.
Department of Electronic Engineering, National Kaohsiung University of Science and Technology, Kaohsiung 82445, Taiwan; 0652807@nkust.edu.tw (L.-Z.C.); f110112104@nkust.edu.tw (T.-Y.C.); ysliang@nkust.edu.tw (Y.-S.L.)

* Correspondence: clshen@nkust.edu.tw; Tel.: +886-7601-1000 (ext. 32515)

\begin{abstract}
A cascaded-like high-step-down converter (CHSDC) is proposed in this article, which can steeply convert a high voltage to a much lower level without the utilizing of extreme turns ratio or duty ratio. The proposed converter integrates two buck-boost converters and one forward converter to form a single-stage architecture containing only a single low-side driving switch, which, as a result, can lower the cost and reduce the complexity of the associated control driver. Even in a single-stage single-switch structure, the ability to step down input voltage is as effective as the cascade of two buck-boosts and one forward converter. Meanwhile, the proposed converter can avoid the low efficiency caused by a cascaded structure. Without an additional clamp circuit, the leakage energy stored in the transformer of the CHSDC can be still recycled so as to raise the efficiency of the converter and suppress voltage spikes at the power switch. Converter operation principle and key parameter design are discussed. Moreover, a $200 \mathrm{~W}$ prototype is built and then tested to validate the proposed converter and verify the theoretical analysis.
\end{abstract}

Keywords: high-step-down converter; single-stage; single-switch; cascaded-like configuration; leakage energy recycling; low-side driving

\section{Introduction}

Even though electric vehicles (EVs) have to be charged, the power for which comes from fossil-fuel plants, EVs can still reduce carbon dioxide production by $60 \%$ as compared with engine-system vehicles. EVs have been challenging the leading position of enginesystem vehicles as a matter of course.

EVs commonly have two built-in DC voltage levels for different kinds of power supply, as shown in Figure 1. The purpose of the high-voltage battery bank is mainly to provide power for motor driving. Meanwhile, the low-voltage lithium-ion battery is for in-car auxiliary appliances such as the panelboard, dashcam, lighting, audio and video systems, air conditioner, automatic seat, and power steering wheel. The low-voltage lithium-ion battery has to be charged from the high-voltage bus. However, the low-voltage battery can alternatively be removed. With this approach, the auxiliary appliances will be powered by the high-voltage bus through a step-down converter with a high conversion ratio. No matter whether a low-voltage lithium-ion battery should be installed in EVs, a high step-down converter to steeply lower bus voltage for powering auxiliary appliances is certainly required.

Conventional step-down converters, such as buck-derived DC/DC converters [1-4], can theoretically accomplish a high voltage-conversion ratio by operating under an extreme duty cycle. However, at the operating of an extreme duty cycle, significant conduction loss and switching loss, high voltage stresses, influential ripples, low efficiency of the converter, etc., will inevitably drop the performance of this kind of converter a lot. For efficiency improvement, among the buck-derived converters, some of them utilize softswitching mechanisms into the converter design to increase efficiency. Nevertheless, an 
acceptable efficiency still cannot be obtained under an extreme duty ratio. As considering isolated topologies, the bridge-derived configurations can be a choice [5-9]. However, in order to obtain a huge conversion ratio, a higher turns ratio has to be adopted, which also decreases converter efficiency and then narrows the conversion range. Besides, multiple active switches will increase costs, the complexity of the drier, and the interference of switching noise.

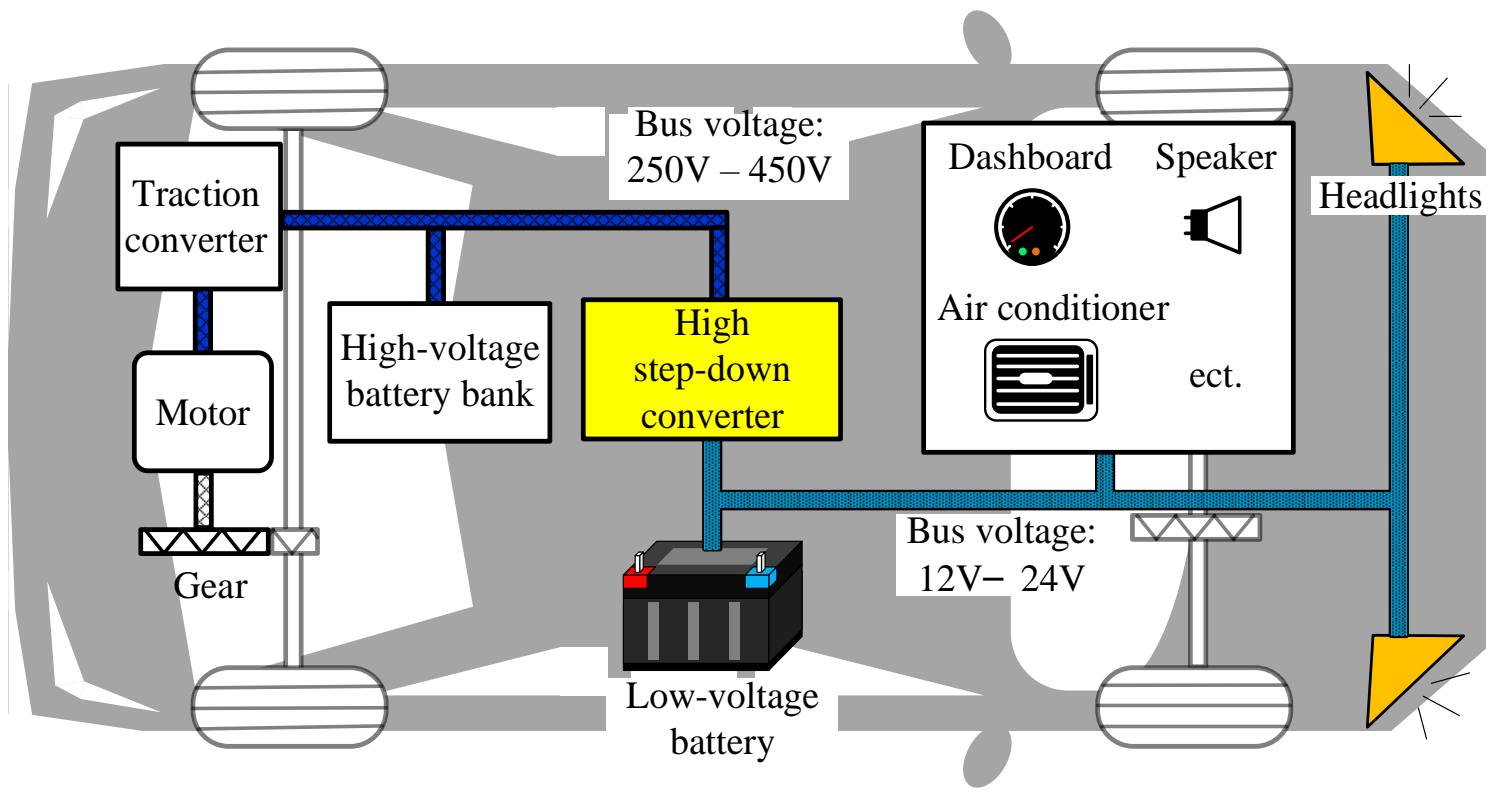

Figure 1. Structure of the power system of electric vehicles.

The structure of a two-/multi-stage converter [10-13] can be an option for achieving an expected voltage gain and for a wide voltage-range operation. With the structure of multi-stages, the parameter tuning will have higher flexibility to average voltage stresses in each stage, which is one advantage of this kind of converter; however, it still has several drawbacks, such as at least two active switches need to be employed and it displays low overall efficiency. Therefore, a cascaded-like converter is developed, which possesses the characteristics of both a high voltage ratio and wide voltage range, the same as that completed by a two-stage converter, and only needs a single switch [14-19]. Nevertheless, their step-down voltage ratios still cannot be as high as for EV applications. Combining transformers into cascaded-like converters to further raise the voltage ratio is, therefore, studied [20-25], but high voltage spikes caused by the leakage inductance of a transformer need to be taken into consideration [21-23]. Usually, a snubber circuit or an active clamped cell is necessarily integrated into converter design [24,25], which accordingly increases cost and circuit complexity.

To step down a high voltage to a much lower level for auxiliary power applications in EV systems as well as overcome the aforementioned problems, a cascaded-like high-stepdown converter (CHSDC) is proposed in this paper. As shown in Figure 2, the CHSDC integrates two buck-boost converters and one forward converter to be a single-switch singlestage architecture. It can accomplish a step-down voltage ratio as high as obtained by the three-stage cascade of two buck-boost converters and one forward converter. In addition, the CHSDC intrinsically has the features of leakage energy recycling and galvanic isolation. 


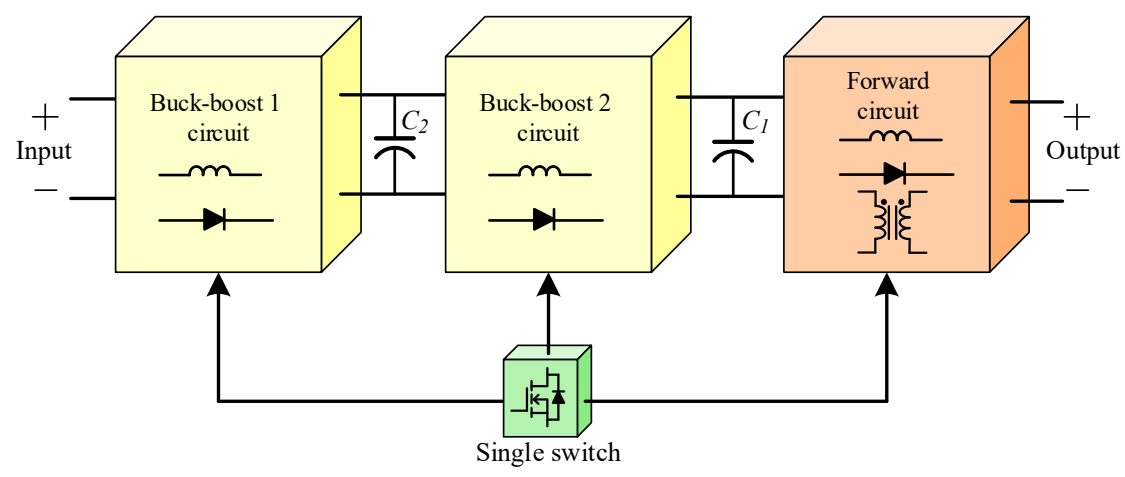

Figure 2. A brief block diagram to illustrate the derivation of the proposed converter.

\section{Converter Structure and Operation Principle}

The main power circuit of the proposed CHSDC is depicted in Figure 3, which is derived from the integration of dual buck-boost converters and a forward converter to construct a single-stage structure with a single switch and galvanic isolation. Even though only one active switch is adopted, the CHSDC is able to step down input voltage as effectively as the cascade type of two buck-boost converters and one forward converter. The cascade of three converters needs three active switches at least, the worst of which belongs to a multi-stage structure, lowering overall efficiency dramatically. Therefore, the CHSDC is much better than the cascade structure.

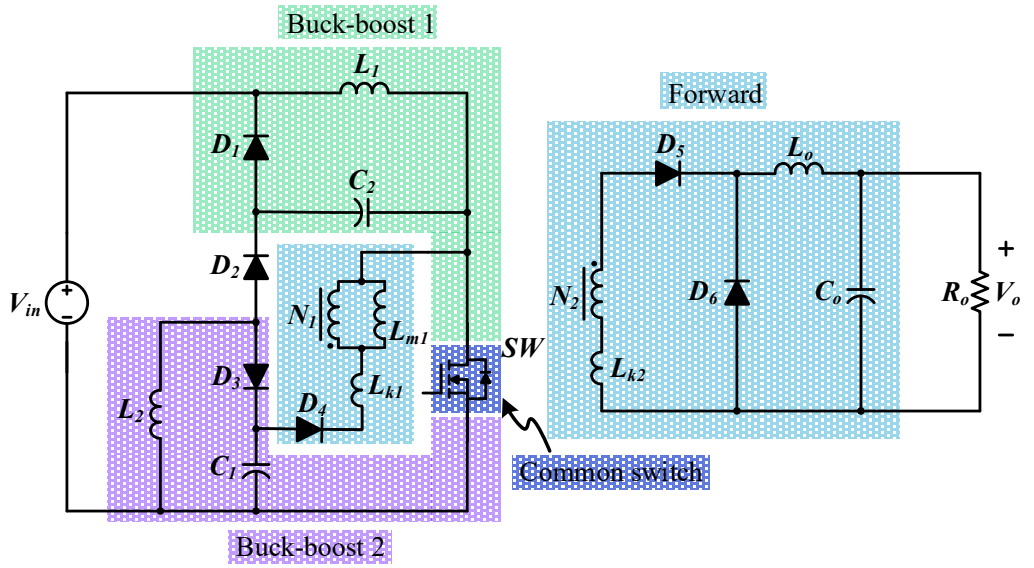

Figure 3. The main power circuit of CHSDC.

As shown in Figure 3, it can be observed that the CHSDC incorporates buck-boost 1 , buck-boost 2, and a forward, only using a common switch but still possessing a high conversion ratio achieved by a cascaded multi-stage converter. In the main power circuit, the equivalent of the high-frequency transformer includes a turns ratio of $N_{2}$ to $N_{1}$, a magnetizing inductance $L_{m 1}$, two leakage inductances $L_{k 1}$ and $L_{k 2}$.

To clearly describe the operation of the CHSDC, the definitions of voltage polarity and current direction are shown in Figure 4. To simplify the analysis, the following assumptions are considered:

1. All the capacitors are large enough so that the voltages across them are regarded as constant and ripple-free;

2. All semiconductor devices and diodes are ideal. That is, parasitic parameters can be neglected;

3. The $L_{k 1}$ and $L_{k 2}$ represent the leakage inductances at the primary side and secondary side of the high-frequency transformer, respectively, values of which both are much smaller than the magnetizing inductance $L_{m 1}$;

4. The duty ratio of the switch $S W$ will be less than 0.5 ; 
5. The turns ratio of the coupled inductor $n$ is equal to $\frac{N_{2}}{N_{1}}$;

6. The inductors $L_{1}$ and $L_{2}$ in the buck-boost circuits and the inductor $L_{o}$ in the forward circuit all operate in continuous conduction mode (CCM).

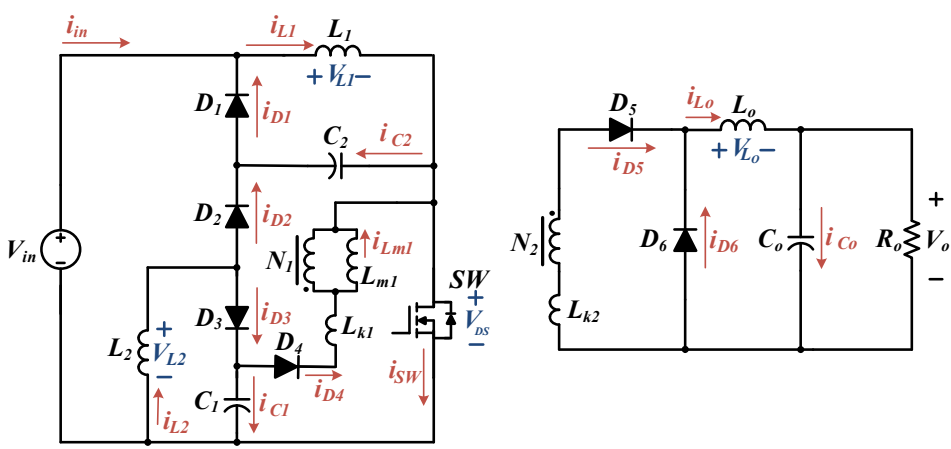

Figure 4. Definitions of voltage polarity and current direction of the proposed converter.

The operation of the proposed CHSDC at steady-state and in CCM can be divided into five modes over one switching cycle. Figure 5 depicts the conceptual key waveforms of this converter, while Figures 6-10 are the equivalents for each mode in turn. In the following, the five operating modes of the converter will be discussed mode by mode.

Mode $1\left[t_{0} \sim t_{1}\right]$ :

As shown in Figure 6, Mode 1 begins when the power switch $S W$ is turned on at $t_{0}$. During the time interval of Mode 1 , diodes $D_{2}, D_{4}, D_{5}$, and $D_{6}$ are in forwarding bias, but diodes $D_{1}$ and $D_{3}$ are reversely biased. During this short-time transition, the current of the leakage inductor $L_{k 1}, i_{L k 1}$ increases linearly. Meanwhile, the current flowing through $L_{k 2}$, $i_{L k 2}$ also increases linearly. The energy of inductor $L_{0}$ is delivered to the load and capacitor $C_{o}$. As the increasing current of $i_{L k 2}$ is equal to the current of $i_{L o}$, the diode $D_{6}$ becomes OFF and this mode ends.

Mode $2\left[t_{1} \sim t_{2}\right]$ :

Mode 2 lasts from $t_{1} \sim t_{2}$. The equivalent circuit of Mode 2 is presented in Figure 7 , which indicates that the $S W, D_{2}, D_{4}$, and $D_{5}$ are still conducting and diodes $D_{1}, D_{3}$, and $D_{6}$ are OFF. Inductor $L_{1}$ absorbs energy from the input voltage, and capacitor $C_{2}$ charges the inductor $L_{2}$ through switch $S W$ and diode $D_{2}$. In addition, capacitor $C_{1}$ forwards its stored energy to the low-voltage side through the high-frequency transformer to supply the output. Thus, the leakage-inductance current $i_{L k 1}$ and magnetizing-inductance current $i_{L m 1}$ are increasing linearly, as does the output-inductor current $i_{L o}$. As the switch $S W$ is turned off, the operation of the converter enters the next mode.

Mode $3\left[t_{2} \sim t_{3}\right]$ :

Mode 3 starts at time $t=t_{2}$. Figure 8 is the related equivalent, where switch $S W$ and diode $D_{2}$ are in OFF state but diodes $D_{1}, D_{3}, D_{4}, D_{5}$, and $D_{6}$ are in ON-state. During this short period, the energy stored in $L_{k 1}$ is recycled to capacitor $C_{2}$ and the input voltage through diode $D_{1}$. At the same time, the leakage energy of $L_{k 2}$ is recycled to the capacitor $C_{o}$ via the diode $D_{5}$. In this mode, capacitor $C_{2}$ is also charged by the inductor $L_{1}$, and capacitor $C_{1}$ is charged by $L_{2}$ via diode $D_{3}$. This mode ends when leakage energy in $L_{k 2}$ releases completely at $t=t_{3}$.

Mode $4\left[t_{3} \sim t_{4}\right]$ :

After leakage inductance releases all stored energy, diode $D_{5}$ becomes OFF and converter operation will be in Mode 4. As illustrated in Figure 9, the switch $S W$ remains OFF and diodes $D_{2}$ and $D_{5}$ are reversely biased. On the contrary, diodes $D_{1}, D_{3}, D_{4}$, and $D_{6}$ are forwarded. Leakage inductance $L_{k 2}$ keeps recycling its energy. In this time interval, the currents $i_{L k 1}$ and $i_{L m 1}$ decrease linearly. On the low-voltage side, output inductor $L_{o}$ still supplies for the output as well as capacitor $C_{0}$. When the leakage-inductance current 
$i_{L k 1}$ and magnetizing-inductance current $i_{L m 1}$ drop to zero at $t=t_{4}$, the next operation mode begins.

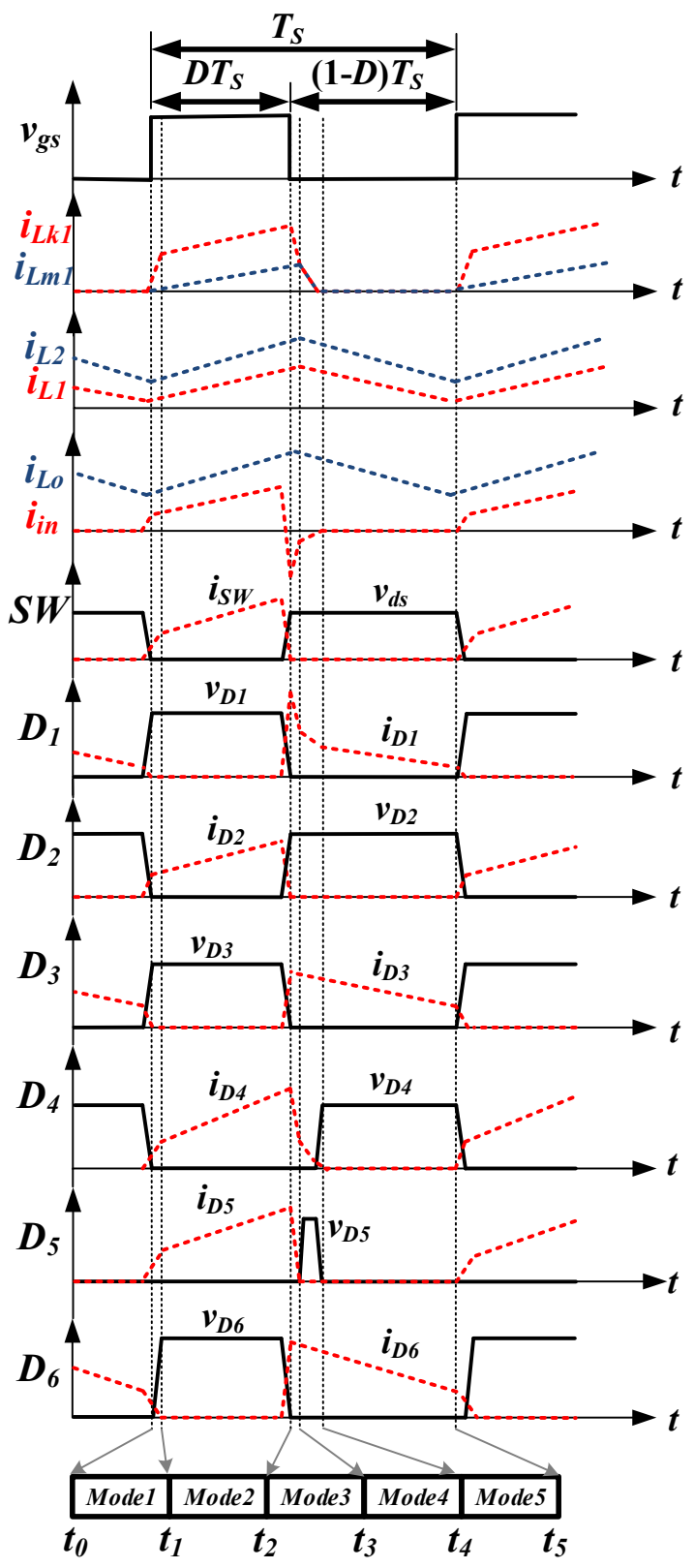

Figure 5. Conceptual key waveforms of the converter in the CCM situation.

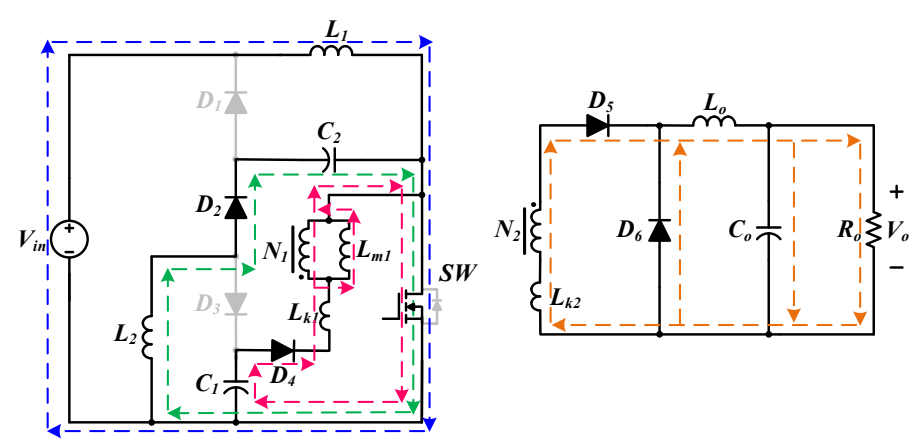

Figure 6. Equivalent circuit of the CHSDC in Mode 1. 


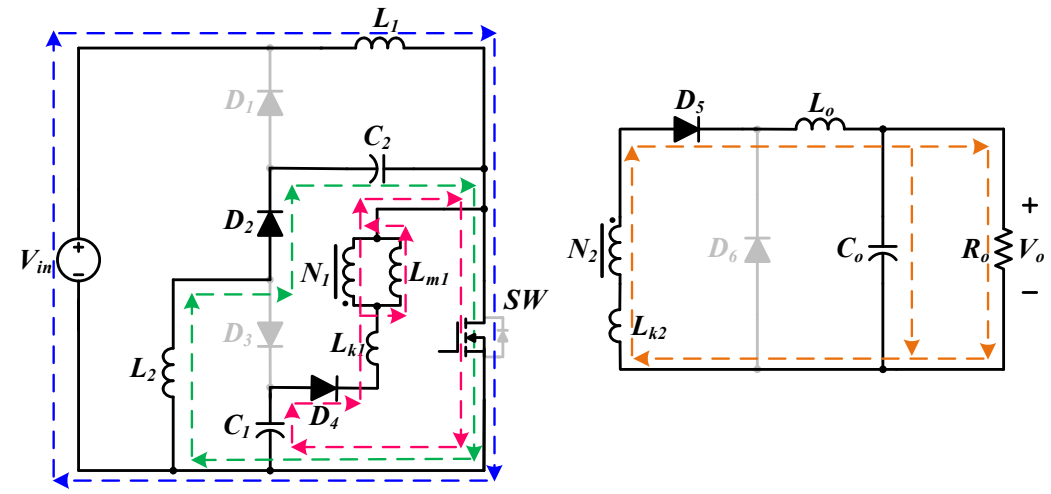

Figure 7. Equivalent circuit of the CHSDC in Mode 2.
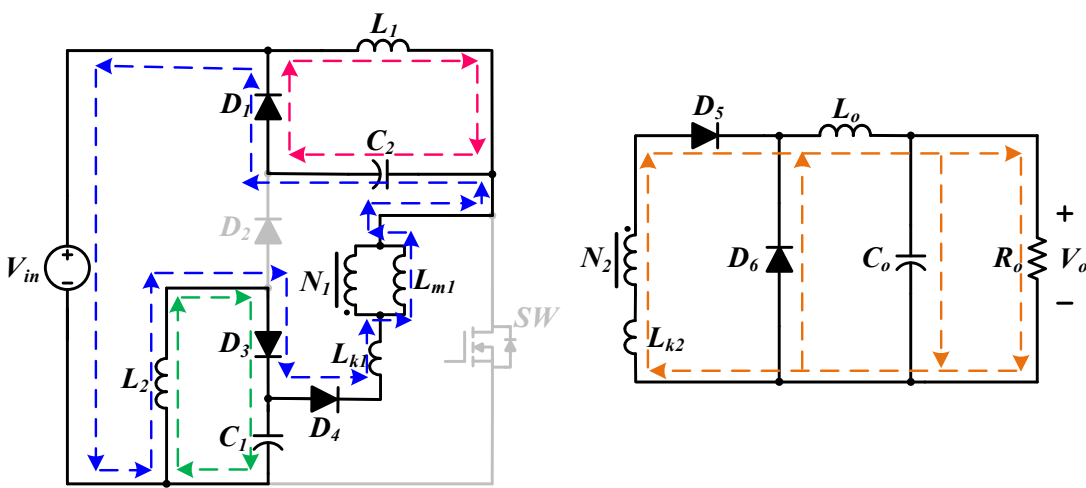

Figure 8. Equivalent circuit of the CHSDC in Mode 3.
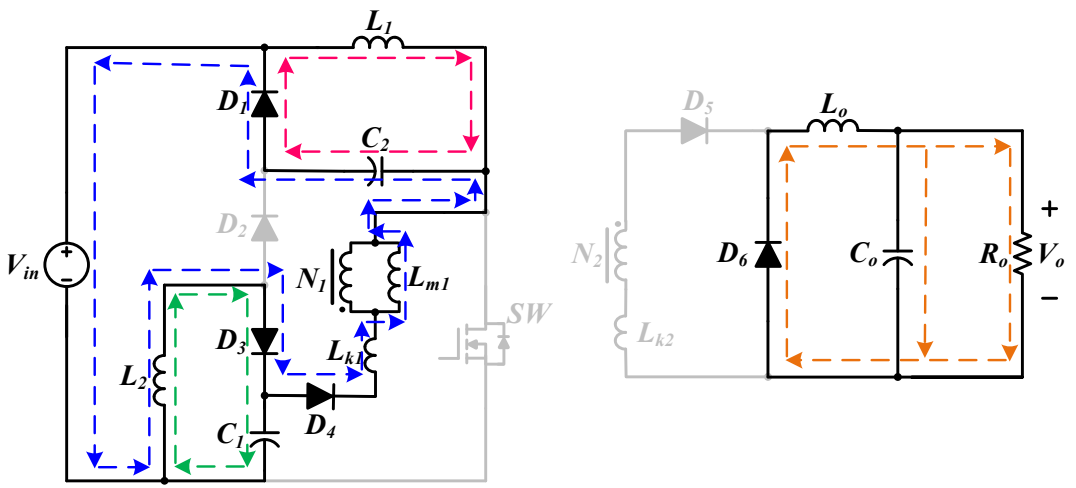

Figure 9. Equivalent circuit of the CHSDC in Mode 4.
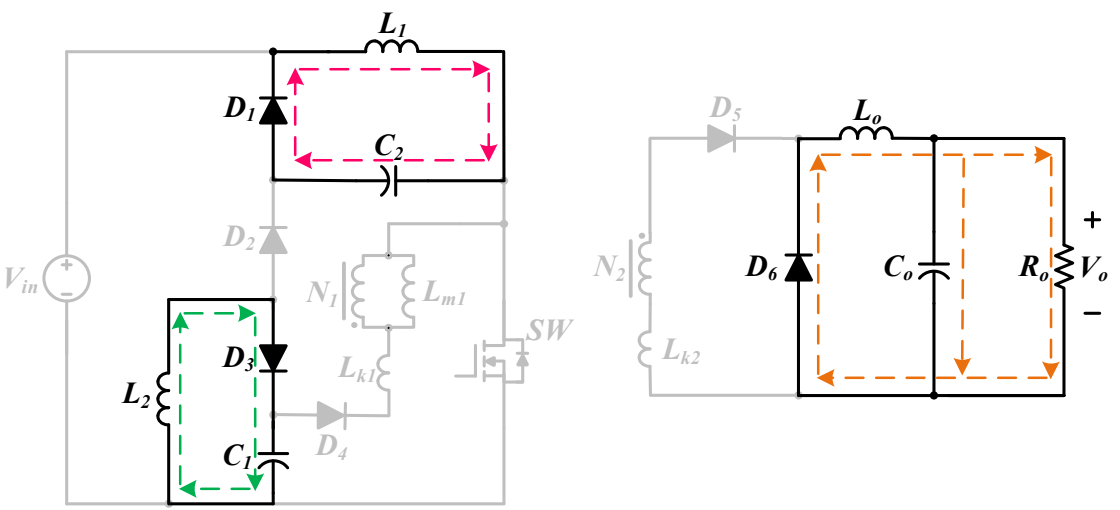

Figure 10. Equivalent circuit of the CHSDC in Mode 5. 
Mode $5\left[t_{4} \sim t_{5}\right]$ :

As indicated in Figure 10, this equivalent circuit is for Mode 5, the switch $S W$ is still in OFF-state, diodes $D_{1}, D_{3}$, and $D_{6}$ are in forwarding bias, and diodes $D_{2}, D_{4}$, and $D_{5}$ are reverse biased. In this mode, capacitor $C_{2}$ is charged by inductor $L_{1}$ through diode $D_{1}$, while inductor $L_{2}$ charges capacitor $C_{1}$ via diode $D_{3}$. The output inductor $L_{o}$ keeps energy-supplying for the load. This mode ends when switch $S W$ is turned on. The complete operation of the converter finishes at $t=t_{5}$.

\section{Steady-State Analysis}

\subsection{Voltage Gain}

The followings discuss the voltage gain derivation of the converter. The definitions of voltage polarity and the current direction are according to Figure 4. Applying the voltage-second balance principle to output inductor $L_{o}$ yields

$$
V_{L o, o n} D T_{s}+V_{L o, o f f}(1-D) T_{s}=0
$$

in which the $V_{L o, o n}$ and $V_{L o, o f f}$ are denoted as the voltages across the inductor $L_{o}$ during the intervals of $S W$ ON and OFF, respectively, $D$ stands for the duty ratio of the active switch, and $T_{S}$ is switching period. As indicated in Figure 7, while $S W$ is in ON state, the voltage of inductor $L_{1}, V_{L 1, o n}$, and the voltage of inductor $L_{2}, V_{L 2, o n}$, can therefore be found as follows:

$$
V_{L 1, o n}=V_{\text {in }}
$$

and

$$
V_{L 2, \text { on }}=V_{C 2}
$$

Additionally, as the switch is $\mathrm{ON}$, the voltage across inductor $L_{o}, V_{L o, o n}$, is expressed as

$$
V_{L o, o n}=n V_{C 1}+V_{o}
$$

When switch $S W$ is OFF, as depicted in Figure 10, the voltages across inductors $L_{1}, L_{2}$, and $L_{o}$ are

$$
\begin{gathered}
V_{L 1, \text { off }}=-V_{C 2} \\
V_{L 2, o f f}=n V_{C 1}+V_{o}
\end{gathered}
$$

and

$$
V_{L o, o f f}=-V_{o}
$$

respectively. By substituting (4) and (7) into (1), the output voltage $V_{o}$ is obtained as

$$
V_{o}=n D V_{C 1}
$$

While applying the criterion of voltage-second balance to the inductors $L_{1}$ and $L_{2}$ individually, the capacitor voltages $V_{C 1}$ and $V_{C 2}$ in terms of duty ratio $D$ and input voltage $V_{\text {in }}$ can be given as

$$
V_{C 1}=\left(\frac{D}{1-D}\right)^{2} V_{i n}
$$

and

$$
V_{C 1}=\left(\frac{D}{1-D}\right) V_{\text {in }}
$$

respectively. Then, substituting (8) into (9), as a result, the converter voltage ratio of output to input is estimated as

$$
\frac{V_{o}}{V_{\text {in }}}=\frac{n D^{3}}{(1-D)^{2}}
$$


While the CHSDC is in CCM operation, the relationship of voltage gain versus switch duty cycle $D$, under different turns ratios of the transformer, is illustrated in Figure 11. It can be observed that the CHSDC is capable of stepping down a high input voltage significantly even under the operating with a regular turns ratio. That is, this converter can avoid employing a high turn-ratio transform. As revealed in Figure 11, the CHSDC achieves a conversion ratio of 0.03 at the conditions that turn ratio is 1:3 and duty cycle is 0.34 . That is, based on this conversion ratio, the CHSDC can deal with a $400 \mathrm{~V}$ input voltage to power a $12 \mathrm{~V}$ load.

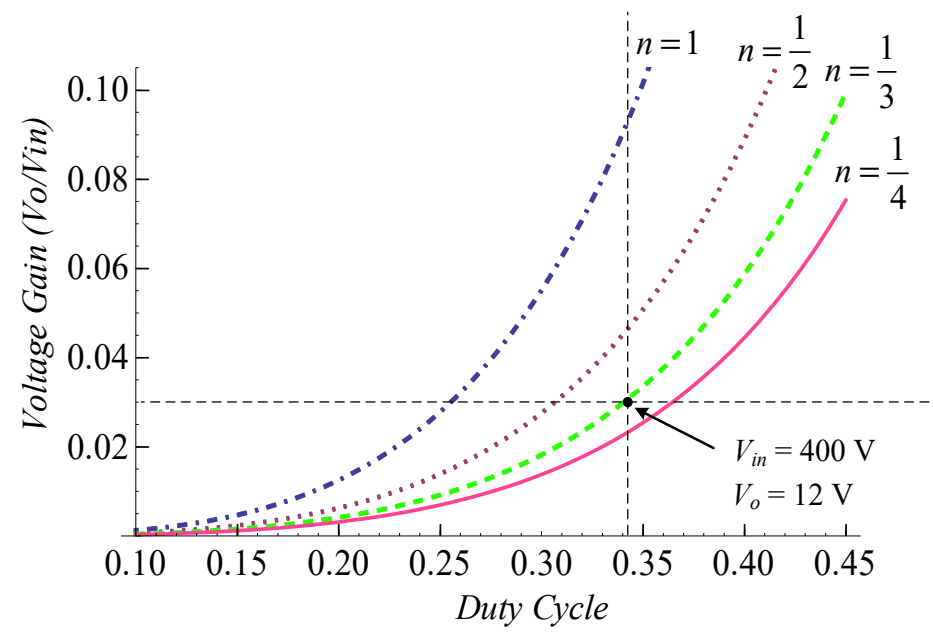

Figure 11. Relationship among voltage gain, duty ratio, and turns ratio.

\subsection{Voltage Stresses of Semiconductors}

In order to choose a proper power switch and diodes, the determination of voltage stress and current stress for each semiconductor device has to be fulfilled. According to Figure 10, during the period of $S W$ OFF, the blocking voltages of the $S W$ and diodes $D_{2}$, $D_{4}, D_{5}$ can be expressed as

$$
\begin{gathered}
V_{S W, \text { stress }}=V_{\text {in }}+\frac{D}{1-D} V_{\text {in }}=\frac{1}{1-D} V_{i n} \\
V_{D 2, \text { stress }}=\frac{1-2 D}{(1-D)^{2}} V_{i n} \\
V_{D 4, \text { stress }}=\frac{1-D-D^{2}}{(1-D)^{2}} V_{i n}
\end{gathered}
$$

and

$$
V_{D 5, \text { stress }}=\frac{1-D-D^{2}}{(1-D)^{2}} n V_{i n}
$$

in turn. Similarly, according to Figure 7, during the period of $S W$ ON, the blocking voltages of diodes $D_{1}, D_{3}$, and $D_{6}$ are, respectively, denoted as follows:

$$
\begin{gathered}
V_{D 1, \text { stress }}=\frac{1}{1-D} V_{i n} \\
V_{D 3, \text { stress }}=\frac{D}{(1-D)^{2}} V_{i n}
\end{gathered}
$$

and

$$
V_{D 6, \text { stress }}=\left(\frac{D}{1-D}\right)^{2} n V_{i n}
$$




\subsection{Current Stresses of Semiconductors}

Since the output inductor $L_{o}$ is in series with the output port, the inductor current $i_{L o}$ will be equal to the output current $i_{o}$ and can be calculated by

$$
i_{L o}=i_{o}=\frac{V_{o}}{R}=\frac{n D^{3} V_{i n}}{R(1-D)^{2}}
$$

In (19), $R$ is the load resistance. As referred to Mode 2 and Mode 5, the inductor current $i_{L o}$ passes through diode $D_{5}$ and diode $D_{6}$ when $S W$ is $\mathrm{ON}$ and OFF, respectively. Therefore, the current stresses of $D_{5}$ and $D_{6}$ will be identical to each other, which are obtained as

$$
i_{D 5, \text { stress }}=i_{D 6, \text { stress }}=i_{L o}=\frac{n D^{3} V_{\text {in }}}{R(1-D)^{2}}
$$

For determining the current stresses of the other semiconductor devices, including $D_{1}$, $D_{2}, D_{3}, D_{4}$, and $S W$, average currents of $L_{m 1}, L_{1}$, and $L_{2}$ along with the capacitor current of $C_{1}$ during SW-ON, that is, $i_{L m 1 \text {,avg }} i_{L 1, a v g}, i_{L 2, a v g}$, and $i_{C 1 \text {,on }}$, have to be found in advance. To comprehend the finding, the waveform of $i_{L m 1}$ is depicted in Figure 12, based on which the current $i_{L m 1, a v g}$ can be computed as

$$
i_{L m 1, a v g}=\frac{\Delta i_{L m 1}}{2}=\frac{\Delta i_{L m 1} D^{\prime} T_{s}}{2 D^{\prime} T_{s}} .
$$

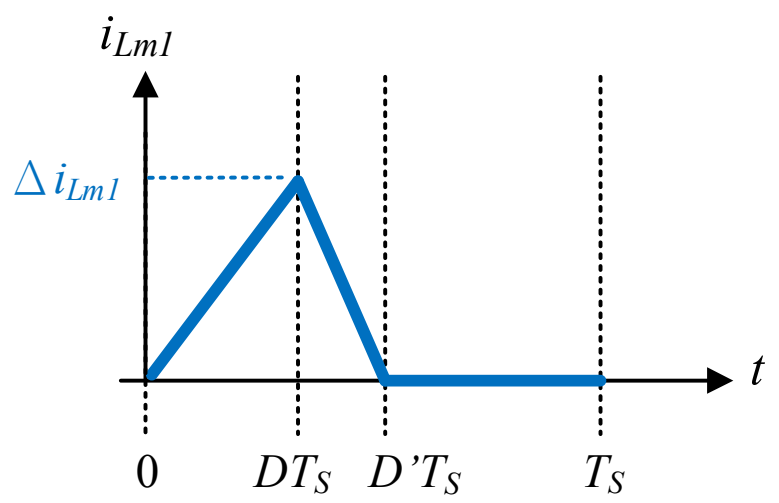

Figure 12. The waveform of magnetizing-inductance current $i_{L m 1}$.

The $\Delta i_{L m 1}$ in (21) is equal to

$$
\Delta i_{L m 1}=\frac{V_{C 1} D T_{s}}{L_{m 1}}
$$

Placing $\Delta i_{L m 1}$ in (22) into (21) yields

$$
i_{L m 1, a v g}=\frac{D T_{s}}{2 L_{m 1}}\left(\frac{D}{1-D}\right)^{2} V_{i n}=\frac{D^{3} T_{s} V_{i n}}{2(1-D)^{2} L_{m 1}}
$$

Based on Mode 2 and Mode 5, the expresses of $i_{L 1, a v g}, i_{L 2, a v g}$, and $i_{C 1, \text { on }}$ can be figured out as follows:

$$
\begin{aligned}
D i_{L m 1, a v g} & =i_{i n} \\
(1-D) i_{L 1, a v g} & =D i_{L 2, a v g}
\end{aligned}
$$

and

$$
(1-D) i_{L 2, a v g}=D i_{C 1, o n}
$$


Suppose that the input power will equal output power. That is,

$$
V_{\text {in }} i_{\text {in }}=V_{o} i_{o}
$$

Since the voltage gain of the CHSDC has been obtained in (11), the input current of the converter can be

$$
i_{\text {in }}=\frac{n D^{3}}{(1-D)^{2}} i_{o}
$$

Substituting both relationships of (19) and (28) into (24), (25), and (26), individually, the currents of $i_{L 1, a v g}, i_{L 2, a v g} i_{C 1, \text { on }}$ are therefore obtained as

$$
\begin{gathered}
i_{\text {L1,avg }}=\left(\frac{n D^{2}}{(1-D)^{2}}\right)^{2} \frac{V_{\text {in }} D}{R} \\
i_{\text {L2,avg }}=\frac{n^{2} D^{4} V_{\text {in }}}{R(1-D)^{3}}
\end{gathered}
$$

and

$$
i_{C 1, o n}=\frac{1-D}{D} i_{L 2, a v g}=\frac{n^{2} D^{3} V_{i n}}{R(1-D)^{2}}
$$

Because the average current flowing through diode $D_{1}$ and the inductance current $i_{L 1, a v g}$ are the same, the following relationship holds:

$$
i_{D 1, a v g}=i_{L 1, a v g}=\left(\frac{n D^{2}}{(1-D)^{2}}\right)^{2} \frac{V_{\text {in }} D}{R}
$$

Besides, the average currents of $D_{2}$ and $D_{3}$ are equal to the inductor current $i_{L 2, a v g}$, which leads to

$$
i_{D 2, a v g}=i_{D 3, a v g}=i_{L 2, a v g}=\frac{n^{2} D^{4} V_{\text {in }}}{R(1-D)^{3}}
$$

Concerning the current stress of $D_{4}$, it can be determined as

$$
i_{D 4, \text { avg }}=i_{C 1, \text { on }}=\frac{n^{2} D^{3} V_{\text {in }}}{R(1-D)^{2}}
$$

For active switch $S W$, Mode 2 is referred and then, its current stress is denoted as

$$
i_{S W, a v g}=i_{L 1, a v g}+i_{L 2, a v g}+i_{C 1, o n}
$$

Substituting (29), (30), and (31) into (35), the current stress of $S W, i_{S W, a v g}$, is then obtained as:

$$
i_{S W, \text { avg }}=\frac{\left(1-D+D^{2}\right) n^{2} D^{3} V_{\text {in }}}{R(1-D)^{4}}
$$

\subsection{Inductance Design}

To guarantee that the converter operation is in CCM, all the minimum currents of the inductors $L_{o}, L_{1}$, and $L_{2}$, that is, $i_{L o(\min )}, i_{L 1(\min )}$, and $i_{L 2(\text { min })}$, are set to be zero and accordingly the following relationships hold:

$$
\begin{gathered}
i_{L o(\min )}=i_{L 2, a v g}-\frac{\Delta i_{L m 1}}{2}=\frac{V_{o}}{R}-\frac{V_{L o}}{2 L_{o}}(1-D) T_{s}=0 \\
i_{L 1(\min )}=i_{L 1, a v g}-\frac{\Delta i_{L 1}}{2}=\left(\frac{n D^{2}}{(1-D)^{2}}\right)^{2} \frac{V_{\text {in }} D}{R}-\frac{V_{\text {in }} D}{2 L_{1} f_{s}}=0
\end{gathered}
$$


and

$$
i_{L 2(\min )}=i_{L 2, a v g}-\frac{\Delta i_{L 2}}{2}=\frac{n^{2} D^{4} V_{\text {in }}}{R(1-D)^{3}}-\frac{V_{\text {in }} D^{2}}{2 L_{2}(1-D) f_{s}}=0
$$

Based on (37)-(39), the required minimum inductances of $L_{0}, L_{1}$, and $L_{2}$, denotes as $L_{o(\text { min })}, L_{1(\text { min })}$, and $L_{2(\text { min })}$, respectively, to ensure the CHSDC is in CCM are determined as

$$
\begin{gathered}
L_{o(\min )}=\frac{R(1-D)}{2 f_{s}} \\
L_{1(\min )}=\frac{R(1-D)^{4}}{2 n^{2} D^{4} f_{s}}
\end{gathered}
$$

and

$$
L_{2(\min )}=\frac{R(1-D)^{2}}{2 n^{2} D^{2} f_{s}}
$$

\subsection{Capacitance Design}

In the CHSDC, the larger the capacitances are, the smaller the voltage ripples become. In order to suppress voltage ripples within the requirements, estimating for the minimum capacitances should be fulfilled. Voltage variation on a capacitor is given as

$$
\Delta V=\frac{i_{C} \Delta t}{C}=\frac{\Delta Q}{C}
$$

with (43), the capacitances of $C_{1}, C_{2}$, and $C_{o}$ can be derived as:

$$
\begin{aligned}
& C_{1}=\frac{i_{L 2, a v g}(1-D) T_{s}}{\Delta V_{C 1}}=\frac{n^{2} D^{4} V_{\text {in }} T_{s}}{R(1-D)^{2} \Delta V_{C 1}} \\
& C_{2}=\frac{i_{L 1, a v g}(1-D) T_{s}}{\Delta V_{C 2}}=\frac{n^{2} D^{5} V_{\text {in }} T_{S}}{R(1-D)^{3} \Delta V_{C 2}}
\end{aligned}
$$

and

$$
C_{o}=\frac{1}{2} \frac{T_{s}}{2} \frac{\Delta i_{L o}}{2 \Delta V_{o}}=\frac{n D^{3} V_{\text {in }} T_{S}}{8 R(1-D)^{2} \Delta V_{o}}
$$

The equivalent series resistance (ESR) in a capacitor will dissipate power and thus lower converter efficiency. It seems that a much higher capacitance should be designed, however, which raises the cost. Therefore, an appropriate capacitance should compromise with voltage ripples. When building the CHSDC prototype, we consider to the voltage ripples of the capacitors $C_{1}, C_{2}$, and $C_{o}$ should be under $1 \mathrm{~V}, 5 \mathrm{~V}$ and $0.1 \mathrm{~V}$, when the capacitance of each capacitors are $47 \mu \mathrm{F}, 4.7 \mu \mathrm{F}$ and $470 \mu \mathrm{F}$.

\subsection{Performance Comparison}

Table 1 summarizes the comparison of the proposed converter with other step-down converters. The performance comparison includes voltage gain, the numbers of semiconductor devices, the numbers of capacitors and magnetic elements, isolation features, and the ability of leakage-energy recycling. Table 1 reveals that the merits of the proposed converter contains: having the mechanism of leakage-energy recycling, a lower number of switches, lower capacitance used, and a better voltage gain. As illustrated in Table 1, even though the proposed CHSDC only requires a single power switch, it can still achieve an excellent step-down competence over all possible range of duty ratios, almost surpassing other similar converters. In addition, the CHSDC has the mechanism of leakage-energy recycling and the feature of galvanic isolation. There are six diodes in the proposed converter, which would imply that, because more diodes are utilized, conversion efficiency would be dropped dramatically. However, among all diodes in the CHSDC, two diodes 
are located on the low-voltage side. The low-voltage diodes can avoid the converter from consuming too much power. Concerning the number of magnetic elements, since the proposed converter is mainly derived from the integration of two buck-boosts and one forward converter, theoretically, the converter will contain more magnetic components. Nevertheless, from the viewpoint of gaining a higher voltage ratio, it is worthwhile. The designs of the magnetic components are in DCM while operating below two-thirds of the load, which means that lower inductances can be considered. Conduction loss can be accordingly restrained. In addition, leakage energy stored in the transformer of the CHSDC can be recycled. Owing to the inductor design and energy-recycling competence, even though more magnetic components are used, power loss still can be suppressed.

Table 1. Performance comparison among the proposed converter and other recently proposed topologies.

\begin{tabular}{cccccc}
\hline Ref. & {$[3]$} & {$[10]$} & {$[14]$} & [25] & Proposed \\
\hline Voltage gain & $\frac{D}{2-D}$ & $\frac{D}{n}$ & $\frac{D}{2}$ & $n D^{2}$ & $\frac{n D^{3}}{(1-D)^{2}}$ \\
\hline MOSFETs & 2 & 6 & 1 & 3 & 1 \\
\hline Diodes & 2 & 0 & 3 & 3 & 6 \\
\hline Capacitors & 3 & 3 & 2 & 3 & 3 \\
\hline Magnetic elements & 3 & 2 & 2 & 3 & 4 \\
\hline Galvanic isolation & No & Yes & No & Yes & Yes \\
\hline Leakage energy recycling & - & Yes & - & Yes & Yes \\
\hline
\end{tabular}

\section{Experimental Results}

To prove the theoretical derivation, illustrate the performance, and verify the validity of the CHSDC, a $200 \mathrm{~W}$ prototype is constructed and then tested. The input voltage of the converter is $400 \mathrm{~V}$ and the output voltage is $12 \mathrm{~V}$. The key parameters of the prototype are summarized in Table 2. Figure 13a shows the waveforms of the practical input current and the related control signal, while Figure $13 \mathrm{~b}$ is the corresponding simulations. Figure 13 reveals that the practical measurements can be consistent with the simulations. In addition, Figure 13 also illustrates that energy stored in leakage inductance can be recycled to the input source and the converter can avoid extreme duty-cycle operation even under the full-load condition. The duty ratio of the switch is close to 0.34 , instead of operating in a heavy-duty ratio. Figure 14 is the voltage and current waveforms of the active switch with practical measure and simulation. It reveals that the average current of the switch is about $9.5 \mathrm{~A}$, which is close to the calculation result of $9.91 \mathrm{~A}$ with (36). The current stresses of $D_{1}-D_{6}$ are calculated with (20) and (32)-(34), individually, then to be $1.48 \mathrm{~A}, 2.87 \mathrm{~A}$, 2.87 A, 5.5 A, 16.6 A, and 16.6 A, respectively, all of which match with the measurement results of $i_{D 1}$ to $i_{D 6}$ in Figure 15. In addition, Figure 15a,g demonstrates that diodes $D_{1}$ and $D_{4}$ both have the feature of zero-current switching (ZCS) during the turn OFF transition. Experimental and simulated current and voltage waveforms of inductors and the output capacitor are also presented in Figures 16 and 17, respectively. Figure 16b shows the simulated inductor currents $i_{L 1}$ and $i_{L 2}$, while Figure 16a is their practical measurements. From Figure 16, it can be observed that the inductors $L_{1}$ and $L_{2}$ are in DCM and CCM, respectively, which have confirmed the theoretical derivation in Section 3.4. Figure $17 \mathrm{~b}$ is the simulated output voltage $v_{0}$ and output inductor $i_{L o}$, practical measurements of which are demonstrated in Figure 17a. As shown in Figure 17, it can be found that the output inductor $L_{o}$ is in CCM, and the output voltage is controlled at a stable level of $12 \mathrm{~V}$ with a quite small ripple of less than $1 \%$. 
Table 2. Parameters and components used in the prototype.

\begin{tabular}{cc}
\hline Parameters & Values \& Specifications \\
\hline$V_{\text {in }}$ (Input voltage) & $400 \mathrm{~V}$ \\
$V_{o}$ (Output voltage) & $12 \mathrm{~V}$ \\
$f_{s}$ (Switch frequency) & $50 \mathrm{kHz}$ \\
Power rating & $200 \mathrm{~W}$ \\
$L_{m 1}$ (Magnetizing inductance) & $366 \mu \mathrm{H}$ \\
$L_{k 1}$ (Leakage inductance) & $2.3 \mu \mathrm{H}$ \\
$L_{1}$ (Inductor) & $648 \mu \mathrm{H}$ \\
$L_{2}$ (Inductor) & $636 \mu \mathrm{H}$ \\
$L_{o}$ (Inductor) & $366 \mu \mathrm{H}$ \\
$S W$ (Power MOSFET) & Netherlands \\
& DSEP29-06A $(600 \mathrm{~V} / 30 \mathrm{~A})$, Leiden, \\
$D_{1}$ (Diode) & Netherlands \\
& BYC8-600 (600 V/8 A), Eindhoven, \\
$D_{2}$ and $D_{3}$ (Diode) & Netherlands \\
$D_{4}$ (Diode) & SDP30S120 (1200 V/30 A), Starkville, MS, USA \\
$D_{5}$ and $D_{6}$ (Diode) & DSSK 60-02A $(200 \mathrm{~V} / 2 \times 30$ A), Leiden, \\
$C_{1}$ (Electrolytic capacitor) & Netherlands \\
$C_{2}$ (Electrolytic capacitor) & $47 \mu \mathrm{F}$ \\
$C_{o}$ (Electrolytic capacitor) & $4.7 \mu \mathrm{F}$ \\
$n$ (Transformer turns ratio) & $470 \mu \mathrm{F}$ \\
\end{tabular}

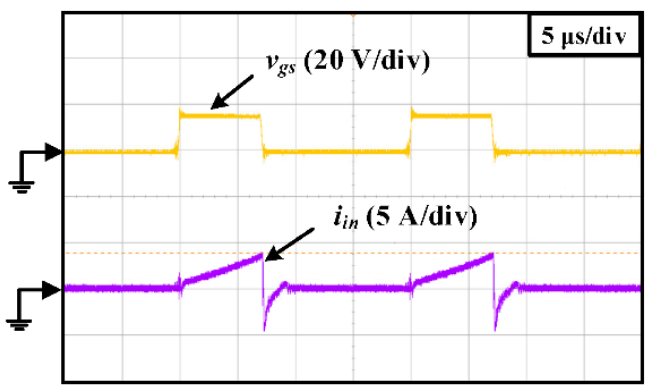

(a)

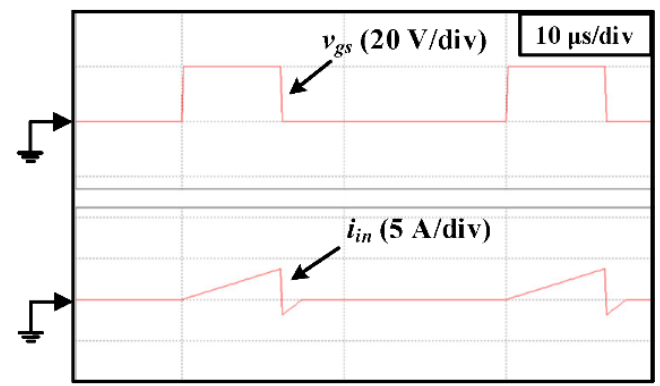

(b)

Figure 13. The waveforms of the control signal and the corresponding input current: (a) measured waveform, (b) simulated results.

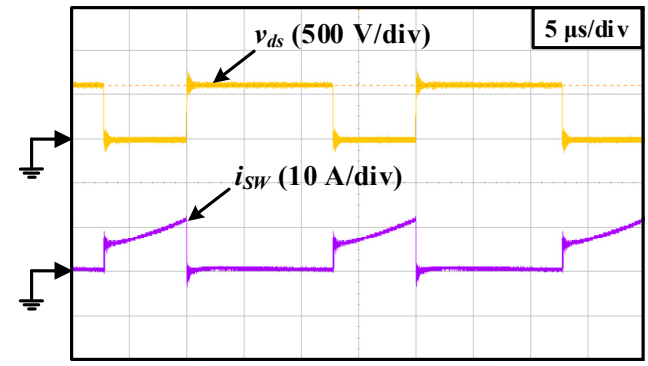

(a)

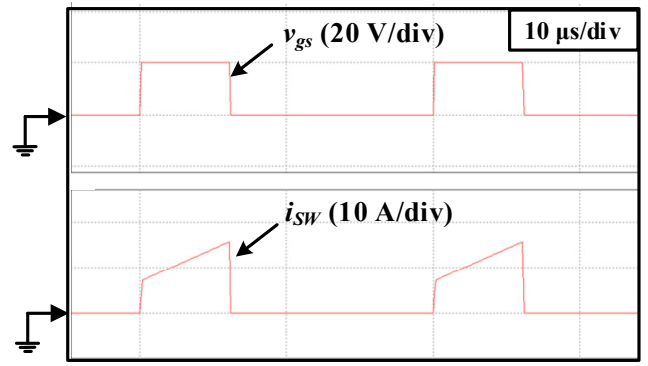

(b)

Figure 14. The waveforms: (a) measured switch voltage and current, (b) simulated control signal and switch current. 


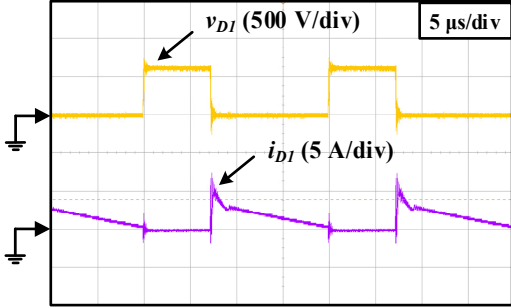

(a)

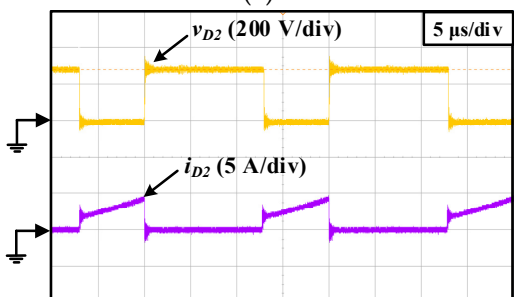

(c)

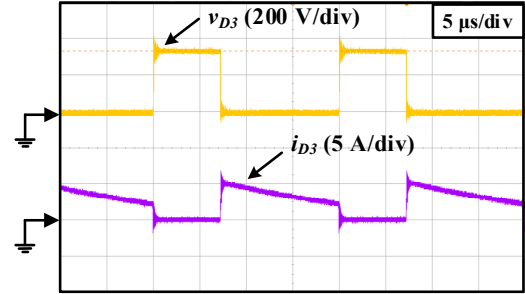

(e)

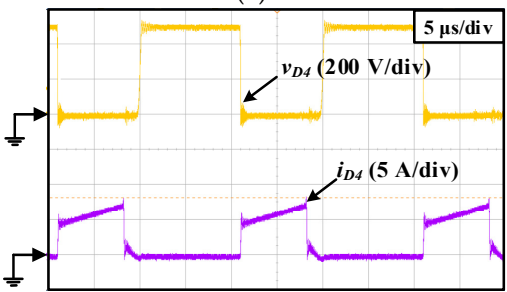

(g)

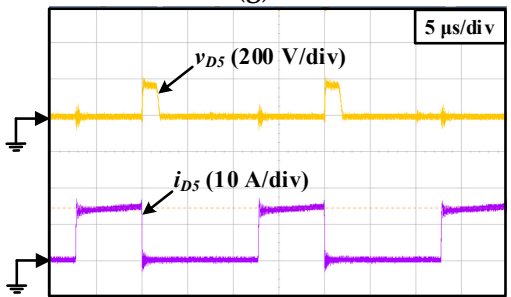

(i)

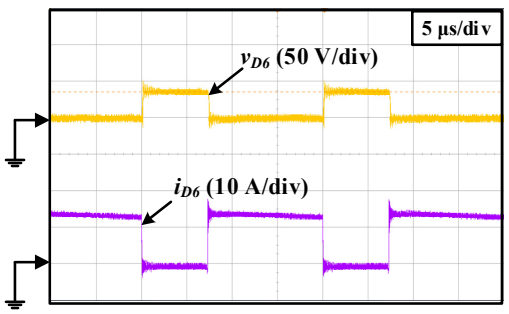

$(\mathbf{k})$
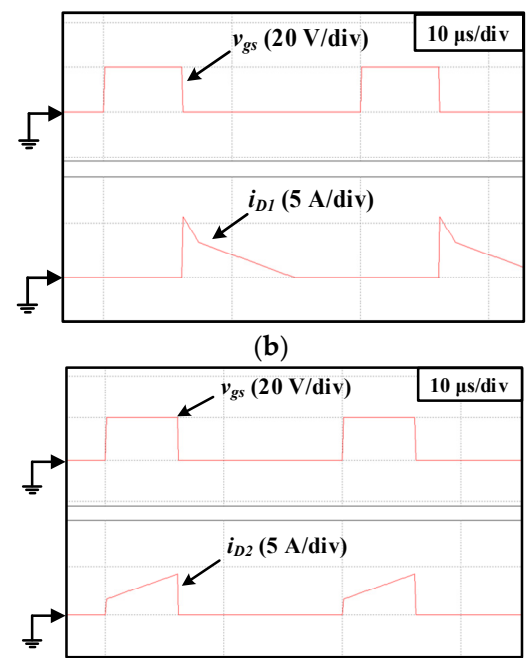

(d)
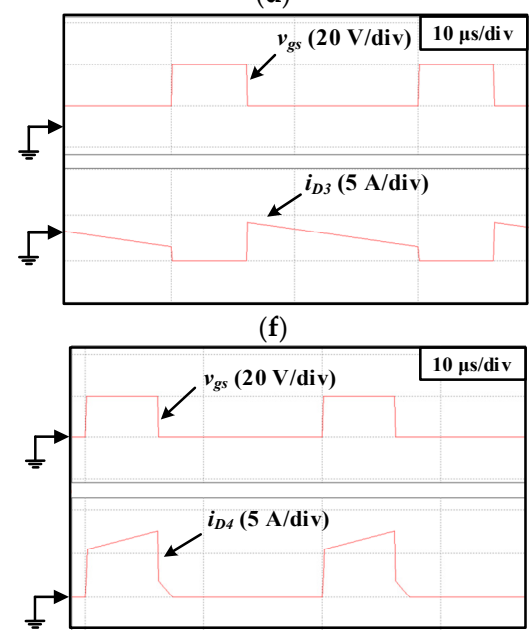

(h)

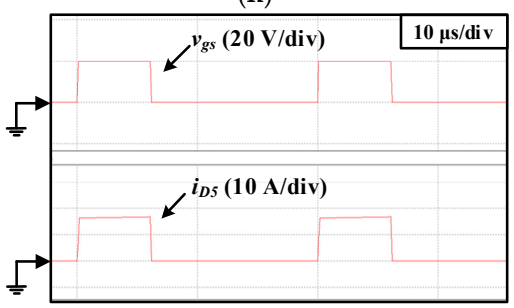

(j)

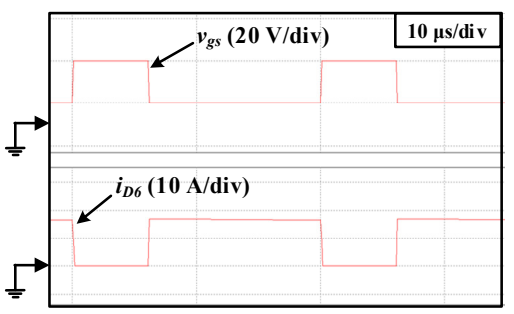

(1)

Figure 15. Measured results and simulations of all diodes in the proposed converter: (a) practical measurements of diode $D_{1},(\mathbf{b})$ simulated results of diode $D_{1},(\mathbf{c})$ practical measurements of diode $D_{2}$, (d) simulated results of diode $D_{2}$, (e) practical measurements of diode $D_{3}$, (f) simulated results of diode $D_{3},(\mathbf{g})$ practical measurements of diode $D_{4},(\mathbf{h})$ simulated results of diode $D_{4}$, (i) practical measurements of diode $D_{5},(\mathbf{j})$ simulated results of diode $D_{5},(\mathbf{k})$ practical measurements of diode $D_{6}$, and (1) simulated results of diode $D_{6}$. 


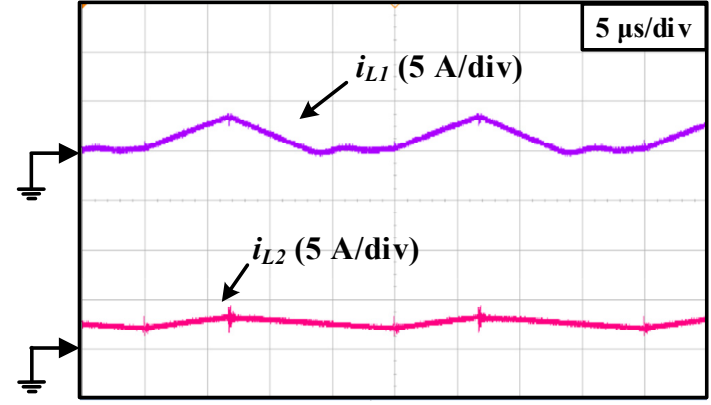

(a)

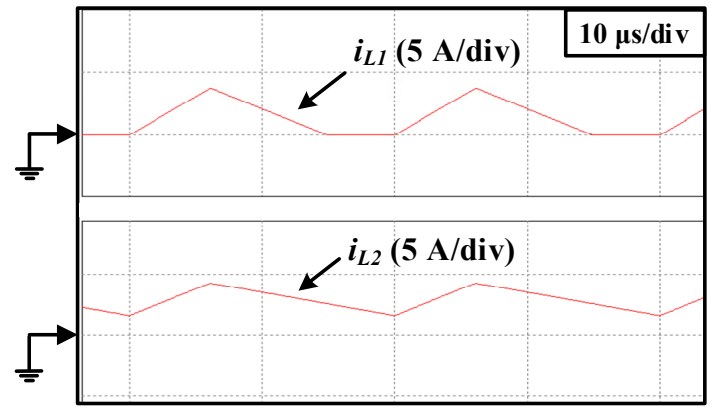

(b)

Figure 16. The waveforms of $i_{L 1}$ and $i_{L 2}:$ (a) practical measurements, and (b) simulated results.

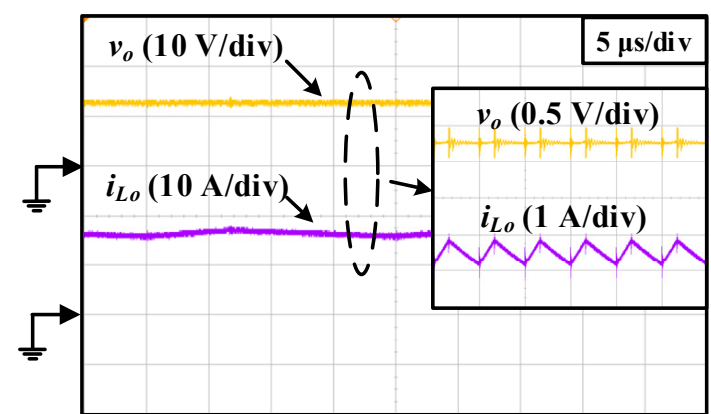

(a)

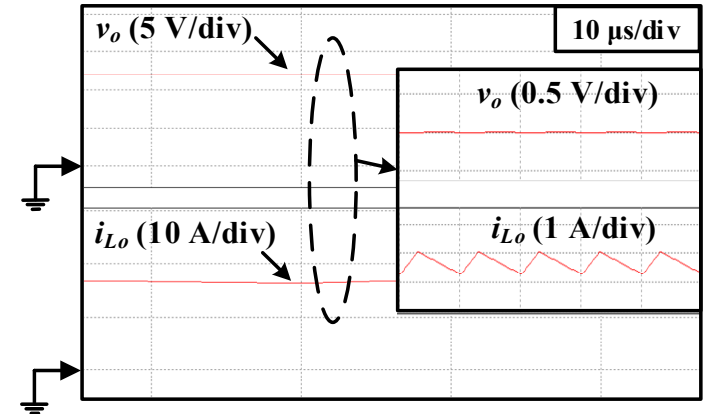

(b)

Figure 17. The waveforms of $v_{0}$ and $i_{L o}$ with zoomed-in observation: (a) practical measurements, and (b) simulated results.

Figure 18 gives the voltage gain of the proposed converter in comparison with the step-down converters in $[3,10,14,25]$. It shows that the proposed converter is better at stepping down a high input voltage than other similar converters. Figure 19 expresses the power budget of the proposed CHSDC while operating in the full-load situation, in which diode loss accounts for $56 \%$ of the total loss. Switch loss accounts for $11 \%$, while inductor loss, transformer loss, and capacitor loss are $15 \%, 11 \%$, and $7 \%$, respectively. The efficiency of the CHSDC is measured per $20 \mathrm{~W}$ from light load to full load. Figure 20 depicts the measured results. From this figure, the highest efficiency is around $93 \%$ at $140 \mathrm{~W}$ and $91 \%$ at the full load. Figure 21 is the photograph of the prototype of CHSDC.

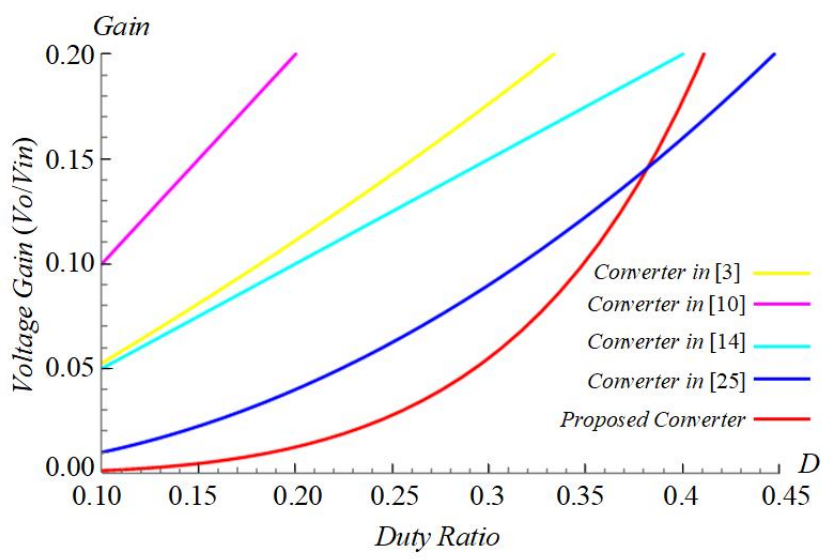

Figure 18. Voltage-gain comparison with other similar converters in $[3,10,14,25]$. 


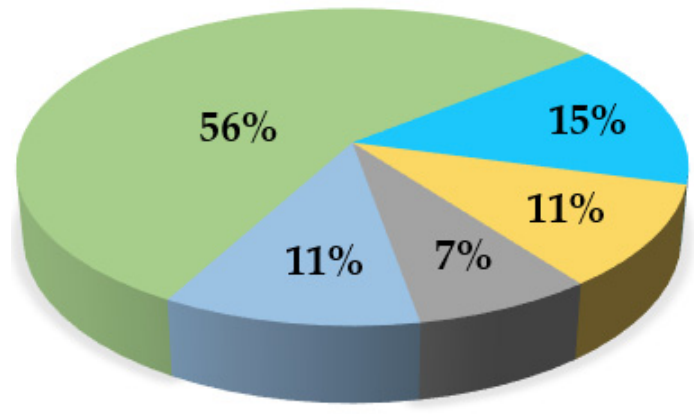

Switch loss

Diode losses

Inductor losses

Transformer loss

Capacitor losses

Figure 19. Power budget of the CHSDC.

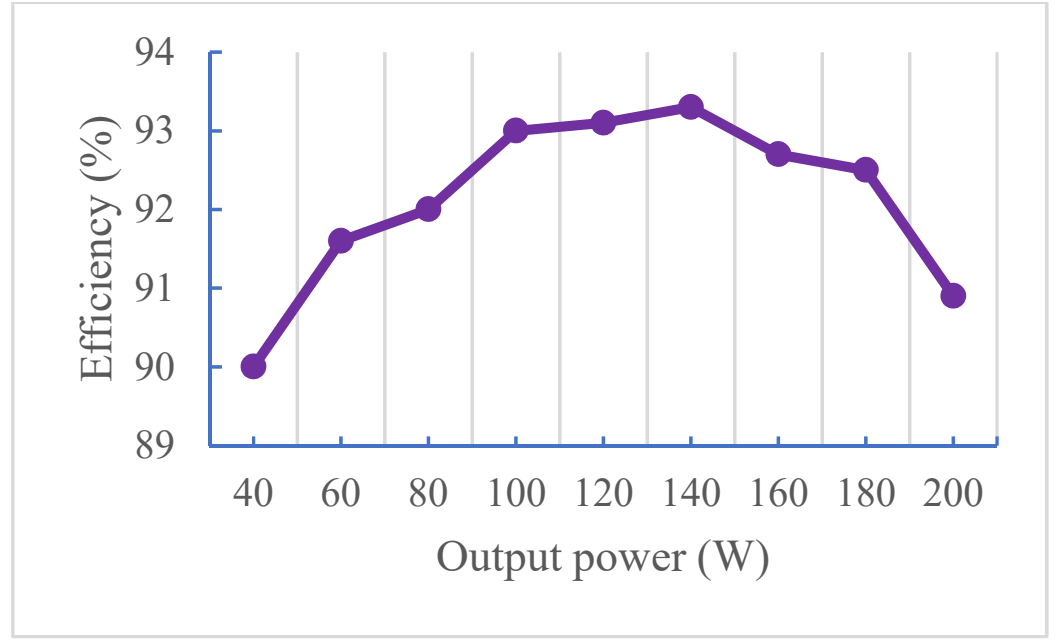

Figure 20. Measured efficiency of the CHSDC from light load to full load.

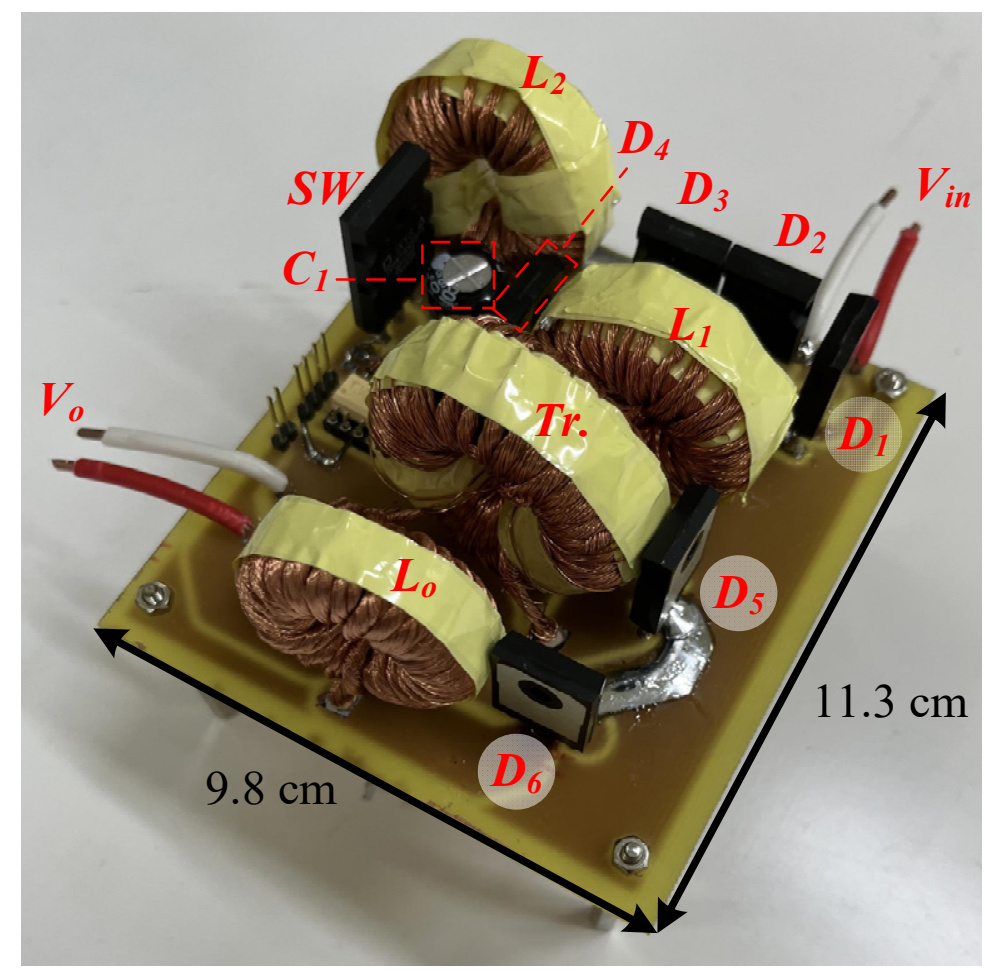

Figure 21. The photograph of the CHSDC. 


\section{Conclusions}

In this article, a high step-down converter is proposed, which is able to accomplish an excellent voltage conversion ratio, avoiding the adopting of high turns ratio and extreme switch cycle. That is, the proposed converter can step down a high input voltage to a much lower level under a regular switch cycle and turns ratio. In the power stage, the CHSDC integrates two buck-boost circuits and one forward circuit to be a single-stage single-switch structure to achieve an excellent voltage conversion ratio which is the same as the effect obtained by the cascade of the three converters. Because only one switch is needed, the complexity of driving circuit design is reduced significantly. The leakage energy stored in the transformer can be recycled for improving the conversion efficiency of the converter and suppressing voltage spikes on the power switch as well. Furthermore, diodes $D_{1}$ and $D_{4}$ possess ZCS-off features. The operation principle, steady-state analysis, and parameter design of the converter in CCM have been explored. Finally, the correctness of the theoretical analysis and the feasibility of the converter are verified through the measurements from a $200 \mathrm{~W}$ prototype.

Author Contributions: Conceptualization, C.-L.S. and L.-Z.C.; methodology, T.-Y.C.; validation, Y.-S.L. and L.-Z.C.; formal analysis, L.-Z.C. and T.-Y.C.; investigation, T.-Y.C. and Y.-S.L.; resources, C.-L.S.; writing-original draft preparation, C.-L.S. and L.-Z.C.; writing-review and editing, C.-L.S. and L.-Z.C.; visualization, L.-Z.C.; supervision, C.-L.S.; project administration, L.-Z.C. All authors have read and agreed to the published version of the manuscript.

Funding: This research received no external funding.

Conflicts of Interest: The authors declare no conflict of interest.

\section{References}

1. Veerachary, M. Two-Switch Semiquadratic Buck Converter. IEEE Trans. Ind. Electron. 2017, 64, 1185-1194. [CrossRef]

2. Hajiheidari, M.; Farzanehfard, H.; Esteki, M. Asymmetric ZVS Buck Converters with High-Step-Down Conversion Ratio. IEEE Trans. Ind. Electron. 2021, 68, 7957-7964. [CrossRef]

3. Esteki, M.; Poorali, B.; Adib, E.; Farzanehfard, H. Interleaved Buck Converter with Continuous Input Current, Extremely Low Output Current Ripple, Low Switching Losses, and Improved Step-Down Conversion Ratio. IEEE Trans. Ind. Electron. 2015, 62, 4769-4776. [CrossRef]

4. Tsai, C.-T.; Shen, C.-L. A High Step-Down Interleaved Buck Converter with Active-Clamp Circuits for Wind Turbines. Energies 2012, 5, 5150-5170. [CrossRef]

5. Choi, S.; Lee, J.; Lee, J. High-Efficiency Portable Welding Machine Based on Full-Bridge Converter with ISOP-Connected Single Transformer and Active Snubber. IEEE Trans. Ind. Electron. 2016, 63, 4868-4877.

6. Pei, X.; Nie, S.; Kang, Y. Switch Short-Circuit Fault Diagnosis and Remedial Strategy for Full-Bridge DC-DC Converters. IEEE Trans. Power Electron. 2015, 30, 996-1004. [CrossRef]

7. Kim, S.; Cha, H.; Ahmed, H.F.; Choi, B.; Kim, H. Isolated Double Step-Down DC-DC Converter with Improved ZVS Range and No Transformer Saturation Problem. IEEE Trans. Power Electron. 2017, 32, 1792-1804. [CrossRef]

8. Lu, Y.; Wu, K.; Xing, Y. A Family of Isolated Buck-Boost Converters Based on Semiactive Rectifiers for High-Output Voltage Applications. IEEE Trans. Power Electron. 2016, 31, 6327-6340. [CrossRef]

9. Lee, S.-S.; Yang, Y.; Siwakoti, Y.P.; Barzegarkhoo, R. Improved Cascaded H-Bridge Multilevel Inverters with Voltage-Boosting Capability. Electronics 2021, 10, 2801. [CrossRef]

10. Liu, Q.; Qian, Q.; Ren, B.; Xu, S.; Yang, L. A Two-Stage Buck-Boost Integrated LLC Converter with Extended ZVS Range and Reduced Conduction Loss for High-Frequency and High-Efficiency Applications. IEEE J. Emerg. Sel. Top. Power Electron. 2021, 9 , 727-743. [CrossRef]

11. Wu, H.; Wan, C.; Sun, K.; Xing, Y. A High Step-Down Multiple Output Converter with Wide Input Voltage Range Based on Quasi Two-Stage Architecture and Dual-Output LLC Resonant Converter. IEEE Trans. Power Electron. 2015, 30, 1793-1796. [CrossRef]

12. Rueschenbaum, T.; Rehlaender, P.; Ha, P.; Grote, T.; Schafmeister, F.; Boecker, J. Two-Stage Automotive DC-DC Converter Design with Wide Voltage-Transfer Range Utilizing Asymmetric LLC Operation. In Proceedings of the PCIM Europe Digital Days 2020; International Exhibition and Conference for Power Electronics, Intelligent Motion, Renewable Energy and Energy Management, Nuremberg, Germany, 7-8 July 2020; pp. 1-7.

13. Eckstein, R.H.; Lazzarin, T.B.; Waltrich, G. Two-Stage SEPIC-Buck Topology for Neighborhood Electric Vehicle Charger. In Proceedings of the 2019 IEEE 15th Brazilian Power Electronics Conference and 5th IEEE Southern Power Electronics Conference (COBEP/SPEC), Santos, Brazil, 1-4 December 2019; pp. 1-4. 
14. Alonso, J.M.; Vina, J.; Vaquero, D.G.; Martinez, G.; Osorio, R. Analysis and Design of the Integrated Double Buck-Boost Converter as a High-Power-Factor Driver for Power-LED Lamps. IEEE Trans. Ind. Electron. 2012, 59, 1689-1697. [CrossRef]

15. Abdelmessih, G.Z.; Alonso, J.M.; Costa, M.A.D.; Chen, Y.-J.; Tsai, W.-T. Fully Integrated Buck and Boost Converter as a High Efficiency, High-Power-Density Off-Line LED Driver. IEEE Trans. Ind. Applicat. 2020, 35, 12238-12251. [CrossRef]

16. Cosetin, M.R.; Bitencourt, E.A.; Bolzan, T.E.; Silva, M.F.; Alonso, J.M.; do Prado, R.N. Comparison of single stage SEPIC and integrated SEPIC-Buck converter as off-line LED drivers. In Proceedings of the 2013 Brazilian Power Electronics Conference, Gramado, Brazil, 27-31 October 2013; pp. 1134-1139.

17. Cosetin, M.R.; Bitencourt, E.A.; Bolzan, T.E.; da Silva, M.F.; Alonso, J.M.; do Prado, R.N. Comparison of integrated SEPIC-Buck and SEPIC-Ćuk converters as off-line dimmable LED drivers with reduced storage capacitor. In Proceedings of the 2014 16th European Conference on Power Electronics and Applications, Lappeenranta, Finland, 26-28 August 2014; pp. 1-10.

18. Almeida, P.S.; Soares, G.M.; Pinto, D.P.; Braga, A.C. Integrated SEPIC Buck-Boost Converter as an Off-line LED Driver without Electrolytic Capacitors. In Proceedings of the IECON 2012-38th Annual Conference on IEEE Industrial Electronics Society, Montreal, QC, Canada, 25-28 October 2012; pp. 4551-4556.

19. Lee, S.; Do, H. A Single-Switch AC-DC LED Driver Based on a Boost-Flyback PFC Converter with Lossless Snubber. IEEE Trans. Power. Electron. 2017, 32, 1375-1384. [CrossRef]

20. Zhang, S.; Wang, Y.; Liu, X.; Xu, D. A single-switch integrated-stage LED driver based on Cuk and Class-E converter. In Proceedings of the 2018 International Power Electronics Conference (IPEC-Niigata 2018-ECCE Asia), Niigata, Japan, 20-24 May 2018; pp. 934-938.

21. Abdelmessih, G.Z.; Alonso, J.M.; Costa, M.A.D. Loss Analysis for Efficiency Improvement of the Integrated Buck-Flyback LED Driver. IEEE Trans. Ind. Applicat. 2018, 54, 6543-6553. [CrossRef]

22. Yadav, V.K.; Verma, A.K.; Yaragatti, U.R. An Integrated Single Switch AC-DC System for LED Driven by an Unconventional Rectifier. In Proceedings of the 2020 IEEE International Conference on Power Electronics, Drives and Energy Systems (PEDES), Jaipur, India, 16-19 December 2020; pp. 1-6.

23. Gacio, D.; Alonso, J.M.; Calleja, A.J.; García, J.; Rico-Secades, M. A Universal-Input Single-Stag2e High-Power-Factor Power Supply for HB-LEDs Based on Integrated Buck-Flyback Converter. IEEE Trans. Ind. Electron. 2011, 58, 589-599. [CrossRef]

24. Poorali, B.; Adib, E. Analysis of the Integrated SEPIC-Flyback Converter as a Single-Stage Single-Switch Power-Factor-Correction LED Driver. IEEE Trans. Ind. Electron. 2016, 63, 3562-3570. [CrossRef]

25. Tseng, K.-C.; Li, I.-C.; Cheng, C.-A. Integrated Buck and Modified Push-Pull DC-DC Converter with High Step-Down Ratio. IEEE Trans. Ind. Electron. 2020, 67, 235-243. [CrossRef] 